\title{
Interdisciplinarni timski rad - izazov u suvremenoj rehabilitaciji
}

1 Iva Lončarić

1 Ida Kovač

1 Martina Rilović Đurašin

1 Rosarija Habuš

1 Neven Kauzlarić

1 Klinički zavod za rehabilitaciju i ortopedska pomagala Medicinskog fakulteta Sveučilišta u Zagrebu, Klinički bolnički centar Zagreb, Hrvatska

\section{Sažetak}

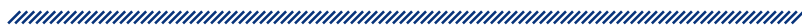

Suvremena rehabilitacija holistički je orijentirana, obuhvaća medicinsku, psihološku i socijalnu dimenziju te počiva na temeljima timskog rada. Restituciju aktivnosti, socijalne participacije i podizanje kvalitete života kod osoba s akutnim/kroničnim zdravstvenim problemom nemoguće je ostvariti kroz djelovanje jedne profesije. Preporuka je Europske udruge medicinskih specijalista (UEMS) ostvarivanje zajedničkih ciljeva rehabilitacije kroz interdisciplinarni pristup, što predstavlja izazov s obzirom na tradicionalni pristup. Kako bi se optimizirao učinak rehabilitacije, nužno je objediniti različite zdravstvene i nezdravstvene profesije; liječnike specijaliste, fizioterapeute, radne terapeute, medicinske sestre, protetičare/ortotičare uz suradnju sa psiholozima, socijalnim radnicima te institucijama koje osiguravaju i odobravaju potrebnu zdravstvenu skrb. U većini zemalja Europe prakticira se isključivo interdisciplinarni oblik rada u rehabilitaciji, problemski orijentiran i fokusiran na bolesnika te ekonomski povoljan za zdravstveni sustav.
Unatoč stručnim kompetencijama i znanju profesionalaca u rehabilitacijskom timu, postoji nedostatak vještina i adekvatnog stava prema interdisciplinarnom radu. Kao posljedica loše komunikacije, različitog gledišta profesija na uloge, hijerarhiju i suradnju u timu, nerazumijevanja ili neprihvaćanja stručnih kompetencija drugih članova, kompromitiran je interdisciplinarni pristup. Tijekom Domovinskog rata rehabilitacija u Hrvatskoj dobiva zamah i potrebu za interdisciplinarnim radom, gdje se unatoč deficitu potrebnih profesija i nepovoljnim paramedicinskim čimbenicima mijenja strateški pristup s holističkim orijentirom. No Hrvatska i njezin sustav zdravstvene skrbi još uvijek su u tranziciji s evidentnim manjkom svih potrebnih stručnjaka, sudionika u rehabilitaciji. Literatura predlaže interdisciplinarni oblik kao jedini oblik rada u suvremenoj rehabilitaciji, no prakticiranje tog oblika rada u esenciji je izazov. $U$ akademskom obrazovanju posebno mjesto mora zauzimati razvijanje vještina kako bi taj izazov postao ustaljena praksa.

Ključne riječi: rehabilitacija, suradnja, interdisciplinarni tim

Datum primitka: 05.04.2016.

Datum prihvaćanja: 05.10.2016.

Adresa za dopisivanje:

Iva Lončarić, dipl. physioth.

Klinički zavod za rehabilitaciju i ortopedska pomagala Medicinskog fakulteta Sveučilišta u Zagrebu, Klinički bolnički centar Zagreb, Hrvatska

Božidarevićeva 11

Tel. 01/2367-915

E-pošta: specfiz.iva@gmail.com 


\section{Uvod u suvremenu rehabilitaciju}

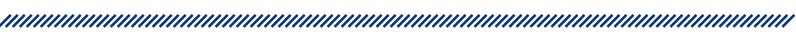

Harvey Cushing (1869. - 1939.), otac moderne neurokirurgije, početkom 20. stoljeća navodi kako je liječnik dužan uzeti u obzir više od bolesnog organa, čak i više od čovjeka u cjelini - mora vidjeti čovjeka u njegovu svijetu, cjelinu u životnoj okolini. Već tada počinje stvaranje temelja holističkog pristupa bolesniku, na kojem se kasnije gradi i danas počiva suvremena rehabilitacijska doktrina. Interes za rehabilitacijsku medicinu pojavljuje se početkom 20. stoljeća, prijelazom manufakturne proizvodnje $u$ industrijsku, s izrazitim razvojem nakon Drugog svjetskog rata ${ }^{1}$. Prvi odjel rehabilitacijske medicine osnovan je u Švedskoj 1958. godine ${ }^{1}$, dok se u Hrvatskoj kao vrijeme osnivanja prve ustanove za medicinsku rehabilitaciju u Zagrebu navode 1915 . $^{2}$ i $1916 .{ }^{1}$ godina. Od tada teče sustavan razvoj i provedba rehabilitacije u bolničkim, a kasnije i izvanbolničkim uvjetima.

Suvremena rehabilitacija holistički je orijentirana, obuhvaća medicinsku, psihološku i socijalnu dimenziju te počiva na temeljima timskog rada. Kao složen i sveobuhvatan proces, rehabilitacijska medicina uključuje dijagnostiku, procjenu funkcionalnog statusa i onesposobljenosti nakon ozljeda i prilikom bolesti, prirođenih mana i razvojnih poremećaja ${ }^{3}$ te ponovno uspostavljanje funkcija i sposobnosti pojedinca u svrhu što bolje aktivnosti i participacije u životnoj okolini. Svjetska zdravstvena organizacija (WHO - World Health Organisation), definira rehabilitaciju kao koordinirani proces koji potiče aktivnost i sudjelovanje, a zasniva se na načelima biopsihosocijalnog modela bolesti ili nesposobnosti. Stručnjak u rehabilitaciji prilikom opisa i klasifikacije funkcioniranja može se osloniti na svjetski prihvaćen dokument International Classification of Functioning Disability and Health (ICF) ${ }^{4}$, no restituciju aktivnosti, socijalne participacije i podizanje razine kvalitete života kod osoba s akutnim/kroničnim zdravstvenim problemom nemoguće je ostvariti kroz djelovanje jedne profesije $^{5}$. Kako bi se optimizirao učinak rehabilitacije, nužno je objediniti različite zdravstvene i nezdravstvene profesije; liječnike specijaliste, fizioterapeute, radne terapeute, medicinske sestre, protetičare i ortotičare uz suradnju sa psiholozima, socijalnim radnicima ${ }^{6}$ te institucijama koje osiguravaju i odobravaju potrebnu zdravstvenu skrb. Važnost objedinjavanja profesija u tim proizlazi iz činjenice da je medicinska rehabilitacija sastavnica šireg pojma integralne rehabilitacije ${ }^{3}$ i uključuje proces učenja o tome kako živjeti s onesposoblje- njem u danom okruženju ${ }^{7}$. Poticanje bolesnika da bude aktivan i informiran član tima nužno je zbog fizičke i emocionalne prilagode na invaliditet ${ }^{5}$ te bolesnikova feedbacka kako bi identificiranje i rješavanje problema bilo uspješnije. Stručnjaci u rehabilitaciji posjeduju znanje i vještine potrebne za tretman i educiranje bolesnika o tome kako se nositi s emocionalnim stresom ${ }^{5}$ uzrokovanim tjelesnim invaliditetom (tablica 1). Potreba je i pravo pacijenta sveobuhvatna medicinska rehabilitacija $^{8}$, stoga je timski rad uvjet za optimalnu adaptaciju na novonastalu situaciju i reintegraciju u što normalniji život. Za postizanje optimalnoga rehabilitacijskog cilja potrebna je kontinuirana suradnja bolesnika, njegove obitelji i rehabilitacijskoga tima koji planiraju, provode i ostvaruju realni cilj poboljšanja kvalitete života? ${ }^{9}$

\section{Timski rad u doktrini liječenja i rehabilitacije}

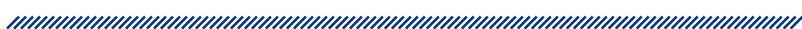

Timski je rad kamen temeljac rehabilitacijske medicine $^{5}$ te „zlatni standard“ u pristupu liječenju bolesnika9. Predstavlja najrašireniji oblik izvođenja složenih profesionalnih zadataka za čije su ostvarenje potrebna znanja iz različitih područja te uže usmjerena znanja iz istog ili sličnih profesionalnih područja ${ }^{10}$. U timu svaki stručnjak ima određenu ulogu koje se mora pridržavati uz akceptiranje uloga drugih članova ${ }^{11}$ te prihvaćanje normi tima i područja rada u kojem djeluje; posredno i neposredno ${ }^{12} \mathrm{~S}$ obzirom na to da tim može djelovati kroz više pristupa, najčešće kroz multidisciplinarni i interdisciplinarni, za organizaciju rehabilitacijske skrbi važno je razlikovati svrhu i princip rada; medicinskog ili rehabilitacijskog modela skrbi

Medicinski model rada uključuje dijagnostiku i liječenje bolesnika u kojem je liječnik samostalan u odlučivanju i predstavlja hijerarhijski vrh - vođu kojem su odgovorni svi članovi tima, svaki sa svojom jedinstvenom intervencijom povezanom s bolesnikom ${ }^{5}$ Vertikalna hijerarhijska komunikacija ${ }^{3}$ u piramidnom obliku ${ }^{7}$ usmjerena $k$ izlječenju bolesti i povratku uobičajenom životu, veže se uz multidisciplinarni timski rad te predstavlja tradicionalan pristup bolesniku.

Rehabilitacijski model rada jedinstven je za proces $u$ kojem se kohezijom profesija odvija ponovno osposobljavanje osobe u svim sferama života - rehabilitaciju. 


\begin{tabular}{|c|c|}
\hline Profesija & Primarna odgovornost \\
\hline $\begin{array}{l}\text { Liječnik u } \\
\text { rehabilitaciji }\end{array}$ & $\begin{array}{l}\text { Ispituje, propisuje dodatne pretrage, dijagnosticira, preporučuje liječenje funkcionalnih poremećaja. } \\
\text { Pomaže pacijentu da se prilagodi na invaliditet i nauči rješavati probleme kako bi se smanjio } \\
\text { funkcionalni gubitak. Vodi momčad, koordinira i tumači izvješća drugih članova tima. }\end{array}$ \\
\hline $\begin{array}{l}\text { Sestra u } \\
\text { rehabilitaciji }\end{array}$ & $\begin{array}{l}\text { Priprema planove sestrinske skrbi, pruža preventivnu i restorativnu skrb (pozicioniranje u krevetu, njega } \\
\text { kože i prevencija oštećenja kože), tretira funkciju crijeva i mokraćnog mjehura, educira pacijenta i obitelj } \\
\text { o samozbrinjavanju. }\end{array}$ \\
\hline Fizioterapeut & $\begin{array}{l}\text { Evaluira, prevenira i tretira poremećaje ljudskog gibanja s pomoću pasivnih i aktivnih vježbi, aplicira } \\
\text { fizikalne modalitete u liječenju, reeducira pacijenta za obavljanje funkcija i aktivnosti, posebno hod uz } \\
\text { pomoć ortoza, proteza, štaka i invalidskih kolica. }\end{array}$ \\
\hline Radni terapeut & $\begin{array}{l}\text { Pomaže pacijentu poboljšati osnovne vještine samozbrinjavanja (oblačenje, jedenje i osobna higijena), } \\
\text { preporučuje adaptivnu opremu, potiče izgradnju kućnih radinosti, očuvanja energije i pojednostavljenja } \\
\text { radnih zadataka, pomaže u poboljšanju komunikacijskih vještina, preusmjerava/usmjerava stručne, } \\
\text { rekreativne i društvene aktivnosti. }\end{array}$ \\
\hline Vokalni terapeut & $\begin{array}{l}\text { Procjenjuje i tretira disfunkcije recepcije, percepcije, dekodiranja, motoričkog planiranja i produkcije } \\
\text { govora. Pomaže u poboljšanju komunikacije, čitanja i pisanja. Procjenjuje i tretira poteškoće u gutanju. }\end{array}$ \\
\hline Socijalni radnik & $\begin{array}{l}\text { Procjenjuje podršku i uslužnost obitelji, služi kao veza između bolesnika, obitelji i zajednice; vodi grupne } \\
\text { rasprave bolesnika i obitelji u suočavanju s teškim invaliditetom. }\end{array}$ \\
\hline Klinički psiholog & $\begin{array}{l}\text { Procjenjuje intelektualne disfunkcije, psihološki utjecaj invaliditeta i motivaciju. Prepoznaje i liječi } \\
\text { reaktivnu depresiju, dizajnira bihevioralnu terapiju i programe treninga socijalnih vještina, prakticira } \\
\text { bračna i seksualna savjetovanja. }\end{array}$ \\
\hline Protetičar & $\begin{array}{c}\text { Dizajnira, izrađuje i aplicira funkcionalna i estetska pomagala u cilju nadomještanja amputiranog dijela } \\
\text { tijela i restitucije funkcije u skladu s radnim i rekreativnim potrebama pacijenta. }\end{array}$ \\
\hline
\end{tabular}

Predstavlja model u kojem sinergijski sudjeluju stručnjaci različitih struka ${ }^{3}$ gdje svaki djeluje u okviru svojeg područja u smjeru ostvarivanja postavljenih rehabilitacijskih ciljeva ${ }^{7}$. Zajedničko djelovanje prema zajedničkom ciljus, holistički usmjereno prema bolesniku, povezano je s interdisciplinarnim timskim radom.

Timski rad ima vrlo visok utjecaj na kvalitetu pružanja zdravstvenih usluga te je važan faktor u funkcioniranju zdravstvenog sustava ${ }^{12}$ i organizaciji zdravstvene, a posebno rehabilitacijske skrbi. Rehabilitacijska je skrb proces koji je potrebno ugraditi u cijeli sustav zdravstvene skrbi, na svim njezinim razinama, jer uključuje prevenciju, rano prepoznavanje, bolničko i ambulantno liječenje te posebne trajne programe kao što je rehabilitacija u zajednici ${ }^{7}$ Timski rad zavisna je varijabla o kojoj će ovisiti ishod rehabilitacije.

\section{Interdisciplinarnost kao faktor izvrsnosti u rehabilitaciji}

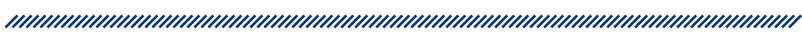

Interdisciplinarni timski rad temelji se na fundamentalnim medicinskim principima, ICF-ovu modelu tjelesnih funkcija, struktura, aktivnosti, participacije i okolišnih čimbenika te znanstveno potkrijepljenim (evidence based) rezultatima u zdravstvenoj skrbi ${ }^{13}$. Interdisciplinarni model jest preferirani model u rehabilitacijskoj skrbi $^{14}$ jer aktivno uključuje onesposobljenu osobu i njezinu obitelj u rad s profesionalcima raznih struka na zajedničkoj zadaći složenoga rehabilitacijskog proce$\mathrm{sa}^{3}$. $\mathrm{U}$ interdisciplinarnom timu u procesu vođenja rehabilitacije bolesnik ima centralnu ulogu ${ }^{7}$, predstavlja fokus djelovanja tima, traži, odlučuje, pomaže i radi sa stručnjacima za dobrobit svojeg životnog funkcioniranja. Komunikacija među članovima tima okarakterizirana je kao lateralna ${ }^{1}$, slobodnim protokom ideja ${ }^{7}$ svaki član tima u svojoj domeni rada djeluje prema ostvarivanju zajedničkih ciljeva rehabilitacije. Interdisciplinarni 
model naglašava formulaciju zajedničkog definiranja i rješavanja problema; višestruke konzultacije stvaraju jedinstveno gledište na bolesnika i njegovu obitelj, često se postavljaju ciljevi tretmana - koordinirano i integrirano $u$ aktivnosti svake profesije ${ }^{5} \mathrm{u}$ rehabilitacijskom timu. U multiprofesionalnom timu uz odgovarajuću razinu znanja i vještina postoji međusobno poštovanje i povjerenje te spremnost na dijeljenje specifičnih znanja - ekspertiza, uz otvorenu komunikaciju između članova. Hijerarhijski, članovi tima na istoj su razini s visokim stupnjem kooperativnosti i međusobne komunikacije ${ }^{15}$, što predstavlja mogućnost većih kvantitativno-kvalitativnih performansi tima s korelativnim učinkom.

Preporuka je Europske udruge medicinskih specijalista (UEMS) ostvarivanje zajedničkih ciljeva rehabilitacije kroz interdisciplinarni oblik timskog rada ${ }^{14}$, što predstavlja izazov s obzirom na tradicionalni, multidisciplinarni oblik. $U$ većini europskih zemalja stručnjaci u rehabilitaciji posjeduju adekvatno znanje i vještine u svojem profesionalnom području s odgovarajućim radnim mjestom unutar institucija u kojima se prakticira interdisciplinarni timski rad $^{5}$. Smatra se da interdisciplinarni oblik timskog rada ima veću kvalitetu suradnje, a time i veću učinkovitost ${ }^{15}$, što mu daje svojevrsnu socioekonomsku prednost u zdravstvenoj skrbi. Multiprofesionalni kliničari suradnjom omogućuju pružanje optimalne skrbi; svaki član tima oslanja se na informacije i akcije drugog člana u timu ${ }^{16}$. $U$ interdisciplinarnom se pristupu učvršćivanjem zajedništva i sinergijskim naporom postiže više nego što jedna profesija može postići sama ${ }^{5}$. U pregledu literature vidljivo je zadovoljstvo članova timova u kojima je pristup interdisciplinarni, no uglavnom uzorak ispitanika s pozitivnim stavom čine medicinske sestre i fizioterapeuti. Veće zadovoljstvo u radu medicinskih sestara vidljivo je unutar tima s interdisciplinarnim pristupom ${ }^{17}$. Fizioterapeuti i medicinske sestre sodjela interne klinike i odjela rehabilitacije većinom smatraju $(56,8 \%)$ kako rade $u$ interdisciplinarnom timu, uz pokazatelj znatno bolje otvorene komunikacije na odjelu rehabilitacije ${ }^{18}$. Timska suradnja interdisciplinarnog tipa u rehabilitaciji primjere dobre kliničke prakse prikazuje kod neuromuskularnih bolesti ${ }^{6}$, ortopedije $^{19}$, ortotike ${ }^{20} i$ protetike ${ }^{3}$, fizikalne medicine i rehabiltacije ${ }^{21}$ i cerebrovaskularnih bolestij ${ }^{22}$, no budući da u većini dostupne literature odnosi između članova tima nisu točno specificirani ${ }^{13}$, a imaju elemente interdisciplinarnosti, možemo smatrati da postoje dokazi o prihvaćenosti pristupa i u drugim područjima.

lako je to preferiran oblik rada, manjak je studija s multiprofesionalnim uzorkom koje bi uspoređivale pristup te efikasnost između interdisciplinarnog i multidisciplinarnog timskog rada ${ }^{15}$, što predstavlja nedostatak za strogi imperativ provođenja prakse temeljene na znanstvenim dokazima.

\section{Izazov u struci i organizaciji rehabilitacijske skrbi}

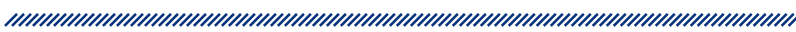

Unatoč stručnim kompetencijama i znanju profesionalaca u rehabilitacijskom timu, postoji nedostatak vještina i adekvatnog stava prema interdisciplinarnom radu. U svim europskim zemljama profesionalci u rehabilitaciji posjeduju adekvatno stručno znanje, no problemi u timskom radu mogu nastati kao posljedica neprikladnih stavova i manjka komunikacijskih vještina ${ }^{5}$. Diskrepantne situacije mogu nastati kao posljedica različitog gledišta profesije na uloge ${ }^{23}$, hijerarhiju i suradnju u timu ${ }^{24}$, ali i kao nerazumijevanje ${ }^{5}$ stručnih kompetencija drugih članova. Opisuju se problemi zavisti, ignoriranja, autoritativnih prijetnji i profesionalnih granica ${ }^{25}$, kao i teškoće u komunikaciji, kooperativnosti i načinu vođenja, uvjetima potrebnima za efikasan timski rad $^{5}$. Interdisciplinarnim oblikom rada centralnu ulogu u procesu vođenja rehabilitacije dobiva bolesnik ${ }^{7}$ i neizbježno je da predstavlja središte u zdravstvenoj skrbi26. Liječnik je u timu „prvi među jednakima“", no dominacija jednog liječnika u timu otežava interdisciplinarni rada ${ }^{27}$. Čest je problem komunikacije i suradnje između samih liječnika ${ }^{28}$. Preklapanje uloga često je prisutno u timu, posebice u djelokrugu rada fizioterapeuta i radnih terapeuta ${ }^{29}$, što potencijalno stvara problem ako komunikacija i percepcija uloga nisu na potrebnoj razini. lako medicinske sestre korektno percipiraju ulogu fizioterapeuta, vrednuju njihovo znanje i vještine, osjećaju se neshvaćeno u svojem području rada i smatraju da postoji manjak autonomije u sestrinskoj profesiji ${ }^{30}$. U predstavljanju problema komunikacije između liječnika i medicinskih sestara navodi se različitost u samoj edukaciji i razvoju komunikacijskih vještina; članovi tima naučeni su različito komunicirati $^{31}$, što potvrđuje činjenicu da sukobi unutar tima najčešće nastaju upravo na području komunikacije ${ }^{32}$. Sve je veći problem u nastajanju konfliktnih situacija između medicinskih sestara i liječnika kao posljedica loših interprofesionalnih odnosa ${ }^{33}$. 
The Joint Commission on the Accreditation of Health $\mathrm{Ca}$ re Organizations (JCAHO) ukazuje na činjenicu da loša komunikacija znatno utječe na pojavu neželjenih događaja i medicinskih pogrešaka ${ }^{34}$.

Jedan od problema za provedbu esencijalnoga interdisciplinarnog rada koji se navodi u literaturi, a vidljiv je svakidašnjoj praksi, manjak je stručnjaka u rehabilitaciji. U nekim zemljama dovoljan je broj medicinskih sestara i fizioterapeuta, ali samo nekoliko radnih i vokacijskih terapeuta djeluje u rehabilitacijskoj skrbi, a socijalni radnici i psiholozi apsolutno su odsutni5. Time većinom fizioterapeuti i medicinske sestre provode terapeutske intervencije, a uže usmjerene intervencije prema aktivnostima svakodnevnog života i kognitivnoj restituciji uopće se ne provode ${ }^{5}$. Tijekom Domovinskog rata rehabilitacija u Hrvatskoj dobiva zamah i potrebu za interdisciplinarnim radom, gdje se unatoč deficitu potrebnih profesija i nepovoljnim paramedicinskim čimbenicima mijenja strateški pristup s holističkim orijentirom, kako bi stradalima pomoć kroz rehabilitaciju bila pružena u svim sferama životnog funkcioniranja. lako članica Europske unije, Hrvatska i njezin sustav zdravstvene skrbi još uvijek su u tranzicijii ${ }^{27}$ s evidentnim manjkom svih stručnjaka sudionika u rehabilitaciji. Time je dostupni kadar primoran pristupati transdisciplinarno; preuzimajući zadatke drugih kada nisu prisutni5. Preuzimanje zadaća nosi sa sobom i preuzimanje odgovornosti, potencijalno stvarajući probleme u funkcioniranju stručnjaka kao individue, na profesionalnoj i osobnoj razini. $U$ radnom okruženju u kojem se naglašava timski pristup u rehabilitaciji velika je vjerojatnost izbijanja tzv. burn out sindroma ${ }^{35}$ ili „izgaranja na poslu“, stanja mentalne i fizičke iscrpljenosti pojedinca. Najšire istraživan model „izgaranja“; sugerira kako je konstrukt sindroma sastavljen od tri faktora: iscrpljenosti, u onoj mjeri u kojoj se zaposlenik osjeća emocionalno iscrpljen i preopterećen radom; depersonalizacije, emocionalnog povlačenja osoblja osjetnog u njihovu radu i osobnog ispunjenja, faktora koji negativno korelira s druga dva konstrukta, a prikazuje u kojoj mjeri članovi imaju osjećaj da njihov rad ima jedinstven, pozitivan doprinos timu i samom korisniku ${ }^{36}$. Većina djelatnika u zdravstvenoj skrbi suočena je s visokom razinom potreba njihovih korisnika ${ }^{35}$. Nedostatak i radna preopterećenost postojećega stručnog osoblja u neadekvatno sastavljenom timu potencira nastanak problema koji posljedično utječu na zdravstvenu skrb; više studija ukazuje na to da izgaranje među zdravstvenim osobljem utječe na korisnikovu percepciju skrbi ${ }^{35}$.

Učinkovit timski rad, posebno interdisciplinarni pristup, može biti kompromitiran svim navedenim problemima ${ }^{37}$.

\section{Transformacijom i edukacijom do optimizacije}

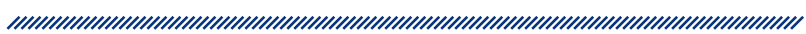

Proces rehabilitacije moguće je optimizirati timskim radom kroz interdisciplinarni pristup, stoga je potrebno poduzeti mjere transformacije timova iz multidisciplinarnih $u$ interdisciplinarne ${ }^{15}$ Kako bi se nadišle moguće barijere, prethodno spomenute u radu, potrebno je razviti kvalitetne smjernice transformacije timova. lako se u nekim publikacijama spominju početni koraci, konkretne mjere i programi još nisu u potpunosti definirani ${ }^{38}$. Poštujući definicije multidisciplinarnog i interdisciplinarnog tima te njihovih normi u menadžmentu i organizaciji te strukturi komunikacije i kooperativnosti, moguća je (re)edukacija u području izvršnih uloga te komunikacijskih vještina u cilju transformacije tima, no nužno je razvijanje i evaluacija konkretnih intervencija za razvoj timova kako bi se etablirao interdisciplinarni pristup $^{15}$.

Akademsko obrazovanje zdravstvenih profila u konstantnom je vertikalnom razvoju. Na veleučilišnoj i sveučilišnoj razini pruža se mogućnost kontinuirane stručne naobrazbe, specijalizacije iz područja interesa polaznika te postizanje najviše razine akademskog stupnja obrazovanja, no u obrazovnim programima manjak je teorijskog i praktičnog dijela posvećenog timskom radu. Formalno obrazovanje stručnjaka u rehabilitaciji u vidu treninga za efikasan timski rad potpuno je odsutno u europskim zemljama ${ }^{39}$ ili se provodi sporadično lokalnom inicijativnom više nego kao nacionalna politika ${ }^{5}$. Učenje o interprofesionalnim odnosima kroz kliničku praksu pruža studentima različitih zdravstvenih smjerova pogled i bolje razumijevanje profesionalnih uloga $\mathrm{i}$ kompetencija ${ }^{40}$, dugoročno pružajući mogućnost kvalitetnoga timskog rada. Komunikacijske vještine inherentne su u zdravstvenoj skrbi jer omogućuju upravljanje sukobima $^{34}$ unutar tima. Razina i stupanj obrazovanja utječu na stavove prema sinergijama u timu, vještinama, inovacijama i kvaliteti timskog rada ${ }^{11}$. Proces razvoja tima, razumijevanje različitih oblika timskog rada i primjena teorije komunikacijskih vještina kroz praksu ${ }^{5}$ imperativ su koji mora biti inkorporiran u obrazovne programe na svim akademskim razinama. 


\section{Zaključak}

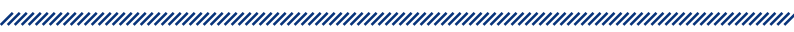

Stručne kompetencije i znanje profesionalaca u rehabilitaciji na zavidnoj su razini u europskim zemljama, no nedostatkom vještina i neadekvatnim stavom prema interdisciplinarnom radu, uz manjak stručnjaka koji čine tim, kompromitira se provođenje kvalitetne zdravstvene/ rehabilitacijske skrbi. Interdisciplinarnost u suvremenoj rehabilitaciji predstavlja izazov, no razvijanjem konkretnih intervencija za razvoj timova moguće je svladati barijere kako bi se etablirao interdisciplinarni pristup. Nacionalnom politikom potrebno je provesti svojevrsnu reformu u obrazovnom programu te implementirati timski rad kroz nastavu u teoriji i praksi svih profesija. Unatoč skromnom broju studija o interdisciplinarnom radu, efikasnost pristupa ipak se temelji na znanstvenim dokazima, stoga je važnost i dužnost pružanja obrazovnog inputa s dugoročnim ciljem rehabilitacijske izvrsnosti. Kao prijedlog u zaključku ističemo partnerski rad obrazovnih institucija u izradi programa formalne izobrazbe, intenzivno i kontinuirano djelovanje osigurano kroz praćenje i kontrolu kvalitete.

\section{Literatura}

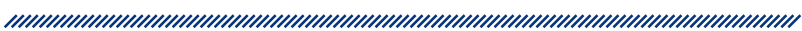

1. Ćurković B. Fizikalna i rehabilitacijska medicina. U: Ćurković B i sur. Fizikalna i rehabilitacijska medicina. Zagreb: Medicinska naklada; 2004:1-3.

2. Jajić I, Jajić Z. Povijesni pregled razvoja fizikalne medicine i rehabilitacije u Hrvatskoj. Fizikalna medicina i rehabilitacija. 1998;15(1-2):27-30.

3. Jelić M. Interdisciplinarni rad u protetici i ortotici. U: Knjiga simpozija: Društvo za protetiku i ortotiku ISPO-Croatia, Tučepi, 2011:11-16.

4. Rauch A, Cieza A, Stucki G. How to apply the International Classification of Functioning Disability and Health (ICF) for rehabilitation management in Clinical practice. European Journal of Physical and Rehabilitation Medicine. 2008;44:329-342.

5. Eldar R, Marincek C, Kullmann L. Need for Rehabilitation Teamwork Training in Europe. Croatian Medical Journal. 2008;49:352-7.

6. Kovač I. Fizioterapija i izbor pomagala u bolesnika s neuromuskularnim bolestima - problemi i mogućnosti. Paediatria Croatica. 2013;57(1):82-86.
7. Laktašić N. Rehabilitacijska medicina. U: Ćurković B i sur. Fizikalna i rehabilitacijska medicina. Zagreb: Medicinska naklada; 2004:3:9-15.

8. Bakran Ž. Modeli timske suradnje u fizikalnoj i rehabilitacijskoj medicini. Fizikalna medicina i rehabilitacija. 2012;24(1):83-87.

9. Žagar I. Rehabilitacijski tim. U: Babić-Naglić i sur. Fizikalna i rehabilitacijska medicina. Zagreb: Medicinska naklada; 2013:11:97-101.

10. Kobolt A, Žižak A. Timski rad i supervizija timova. Ljetopis socijalnog rada. 2007;14(2):367-386.

11. Brumnić V, Šimunović D. Timski rad u fizioterapiji-temelj suvremene rehabilitacijske doktrine. European Journal of Bioethics. 2015;6(11):87-111.

12. Nikić D, Aranđelović M, Nikolić M, Stanković A. Zadovoljstvo poslom kod zdravstvenih djelatnika. Acta Medica Medianae. 2008;47(4):9-12.

13. Neumann V, Gutenbrunner C, Fialka-Moser V, Christodoulou N, Varela E, Giustini A, Delarque A. Intredisciplinary teamworking in physical and rehabilitation medicine. Journal of Rehabilitation Medicine. 2010;42:4-8.

14. Heruti RJ, Ohry A. The rehabilitation team. American Journal of Physical Medicine \& Rehabilitation. 1995;74:466-8.

15. Körner M. Interprofessional teamwork in medical rehabilitation: a comparison of multidisciplinary an interdisciplinary team approach. Clinical Rehabilitation. 2010;24:745-755.

16. Mitchell P, Wynia M, Golden R, McNellis B, Okun S, Webb CE, Rohrbach V, Kohorn IV. Core principles and values of effective team-based health care. Discussion Paper, Washington (DC): Institute of Medicine. 2012:1-30.

17. Hibbert E, Arnaud SS, Dharampaul S. Nurses satisfaction with the patient care team. Canadian Journal of Rehabilitation. 1994;8:87-95.

18. Ivrlač N. Zadovoljstvo timskim radom u zdravstvu. Reumatizam. 2015;62(1):119.

19. Stavrev VP, Ilieva EM. The holistic approach to rehabilitation of patients after total hip joint replacement. Folia Medica. 2003;45(4):16-21.

20. Kovač I, Lončarić I, Horvat K, Kauk L, Palavra H, Flegar B. Izbor ankle foot ortoze kod bolesnika s parezom stopala u kliničkoj praksi. U: Knjiga simpozija: Društvo za protetiku i ortotiku ISPO-Croatia, Poreč, 2014: 41-42.

21. Angst F, Brioschi R, Main CJ, Lehmann S, Aeschlimann A. Interdisciplinary rehabilitation in fibromyalgia and chronic back pain: a prospective outcome study. The Journal of Pain. 2006;7(11):807-15.

22. Galski T, Bruno RL, Zorowitz R, Walker J. Predicting Length of Stay, Functional Outcome, and Aftercare in the Rehabilitation of Stroke Patients. Stroke. 1993;24:1794-1800.

23. Ross A, King N, Firth J. Interprofessional Relationships and Collaborative Working: Encouraging Relflective Practice. The Online Journal of Issuses in Nursing. 2005;10(1):4. doi: 10.3912/OJIN.Vol10No01Man03.

24. Suddick KM, De Souza L. Therapists' experiences and perceptions of teamwork in neurological rehabilitati- 
on: reasoning behind the team approach, structure and composition of the team and team working processes. Physiotherapy Research International. 2006;11:72-83.

25. Gibbon B, Watkins C, Barer D, Waters K, Davies S, Lightbody $L$, et al. Can staff attitudes to team working in stroke care be improved? Journal of Advanced Nursing. 2002;40:105-11. doi: 10.1046/j.1365-2648.2002.02345.x.

26. Reily JM, Aranda MP, Segal-Gidan F, Halle A, Han PP, Harris P, Jordan K, Mulligan R, Resnik C, Tsai KY, et al. Assesment of student interprofessional education (IPE) training for team-based geriatric home care: does IPE training change students knowledge and attitudes? Home Health Care Services Quarterly. 2014;33(4):177-93.

27. Farell MP, Schmitt MH, Heinemann GD. Formal roles and the stages of interdisciplinary team development. Journal of Interprofessional Care. 2001;15:281-95.

28. Ćurković M, Milošević M, Borovečki A, Mustajbegović J. Physicians interpersonal relationships and professional standing seen trought the eyes of the general public in Croatia. Patient Preference and Adherence. 2014;8:11351142. doi:http://dx.doi.org/10.2147/PPA.S65456.

29. Babić-Naglić Đ. Biomehanika, ortopedske i reumatske bolesti, rehabilitacija, tjelesno vježbanje u starijoj dobi. Rehabilitacija. U: Duraković Z i sur. Gerijatrija - Medicina starije dobi. 2 izd. Zagreb: C.T. - Poslovne komunikacije. 2007:508-511.

30. Dalley J, Sim J. Nurses' perceptions of physiotherapists as rehabilitation team members. Clinical Rehabilitation. 2001;15:380-9. doi: 10.1191/026921501678310180.

31. MacKay RC, Matsuno K, Mulligan J. Communication problems between doctors and nurses. International Journal of Health Care Quality Assurance. 1991;3:11-9.
32. Tudor G, Srića V. Menadžer i pobjednički tim: čarolija timskog rada. Zagreb: MEP Consult; 2006.

33. McVicar A. Workplace stress in nursing: a literature review. Journal of Advanced Nursing. 2003;44(6):633-42.

34. Sportsman S, Hamilton P. Conflict management styles in the health professions. Journal of Professional Nursing. 2007;23(3):157-66.

35. Garman AN, Corrigan PW, Morris S. Staff Burnout and Patient Satisfaction: Evidence of Relationships at the Care Unit Level. Journal of Occupational Health Psychology. 2002;7(3):235-241. doi: 10.1037//1076-8998.7.3.235.

36. Maslach C, Jackson SE, Leiter MP. Maslach Burnout Inventory manual, U: Zalaquet CP, Wood RJ. Evaluating Stress. A book of resources, 3. izd. Lanham, MD: Scarecrow Press; 1997: 191-216.

37. De Moor J, Didden R, Nuis M, van de Ven G. Assessing needs for interdisciplinary team training in children's rehabilitation: a pilot study. International Journal of Rehabilitation Research. 1999;22:93-100. doi: 10.1097/00004356-199906000-00003.

38. Davis A, Davis S, Moss N et al. First steps towards an interdisciplinary approach to rehabilitation. Clinical Rehabilitation. 1992;6:237-44.

39. Leonard M, Graham S, Bonacum D. The human factor: the critical importance of effective teamwork and communication in providing safe care. Quality \& safety in health care Institute for Healthcare Improvement. 2004;13(1):85-90. doi: 10.1136/qshc.2004.010033.

40. Hylin U, Nyholm H, Mattiasson AC, Ponzer S. Interprofessional training in clinical practice on a training ward for healthcare students: a two-year follow-up. Journal of Interprofessional Care. 2007;21:277-88. doi: $10.1080 / 13561820601095800$. 


\section{INTERDISCIPLINARY TEAMWORK - CHALLENGE IN CONTEMPORARY REHABILITATION}

Iva Lončarić, Ida Kovač, Martina Rilović Đurašin, Rosarija Habuš, Neven Kauzlarić

Department of Rehabilitation and Orthopaedic Aids, University Hospital Centre Zagreb, Croatia

\section{Abstract}

Modern rehabilitation is holistically oriented, it includes medical, psychological and social dimension and is based on teamwork. Restitution activities, social participation and raising the quality of life in patients with acute/chronic health problem are impossible to achieve by the action of only one profession. The recommendation of the European Union of Medical Specialists (UEMS) is the achievement of common goals of rehabilitation through an interdisciplinary approach, which represents a challenge when compared to the traditional approach. In order to optimize the effect of rehabilitation, it is necessary to consolidate a variety of medical and non-medical professions; specialized medical doctors, physical therapists, occupational therapists, nurses, prosthetists/orthotists in cooperation with psychologists, social workers and institutions that provide and approve the necessary medical care. In most European countries, interdisciplinary forms of work in rehabilitation are exclusively practiced, they are problem-oriented and focused on the patient, and economically beneficial for the health system. Despite the technical competence and knowledge of professionals in the rehabilitation team, there is a lack of adequate skills and attitude towards interdisciplinary work. As a result of poor communication, a different point of view on the role of the profession, hierarchy and cooperation in the team, as well as a lack of understanding or accepting professional competencies of other members, interdisciplinary approach is compromised. During the war, rehabilitation in Croatia gained momentum and the need for interdisciplinary work, and despite the lack of required professions and unfavorable paramedical factors, it changed strategic approach to holistic landmark. However, Croatia and its health care system are still in transition, with an evident lack of expert participants in rehabilitation. Literature suggests interdisciplinary form as the only form of work in contemporary rehabilitation, but practicing the same is in its essence a challenge. In order to transfer this challenge to the common practice, development of appropriate skills deserves a special place in academic education.

Keywords: rehabilitation, cooperation, interdisciplinary team 